Article

\title{
Cultural Influences on Fruit and Vegetable Food-Wasting Behavior in the European Union
}

\author{
Corina Pelau ${ }^{1, *}$, Roxana Sarbu ${ }^{2}$ and Daniela Serban ${ }^{3}$ \\ 1 Department for Business Administration, The Bucharest University of Economic Studies, \\ 010371 Bucharest, Romania \\ 2 Department for Business, Consumer Science and Quality Management, The Bucharest University of \\ Economic Studies, 010371 Bucharest, Romania; sarbu.roxana@ase.ro \\ 3 Department for Statistics and Econometrics, The Bucharest University of Economic Studies, \\ 010371 Bucharest, Romania; danielaserban2011@gmail.com \\ * Correspondence: corina.pelau@fabiz.ase.ro; Tel.: +40-745-581208
}

Received: 21 October 2020; Accepted: 18 November 2020; Published: 20 November 2020

\begin{abstract}
In a context of increased world population and imbalanced access to resources, the concept of food waste has gained increased attention in the past years. The waste of food has a negative impact on the economy, the society and the environment. In order to reduce the quantities of wasted food, it is important to understand the factors and the situations in which food waste occurs. Several studies have shown that food waste happens mostly at the consumer level and that it is determined by a wide range of factors, such as socio-demographic characteristics and consumption patterns. The objective of this paper is to determine the impact of the national culture on the quantity of wasted fruit and vegetables. Based on secondary data, the panel regression analysis was applied for 28 European countries with the purpose of determining the influence of the cultural dimensions as described by Hofstede on the quantities of wasted fruit and vegetables. The results of the research show that the uncertainty avoidance of a culture complemented by the indulgence index influences the quantity of wasted fruit and vegetables, confirming that certain characteristics of the national culture are factors that affect the quantity of wasted food.
\end{abstract}

Keywords: food waste; sustainable consumption; food security; cultural dimensions; Hofstede's model

\section{Introduction}

Food waste and food security have become some of the key priorities of researchers and policy makers in a context of a growing world population, increased pressure toward environmentally friendly actions and changing climate [1]. Several studies have pointed out the increased dimension of food waste and food losses at all levels of the supply chain and their impact on a sustainable food security strategy [2-5]. The huge quantity of wasted food has a negative impact on the economy, on the society and on the environment [6]. Besides the social inequities, by which a part of the population has too much to eat, while others are starving, food waste also contributes to environmental problems. On one hand, there is the problem of the impact of waste on the environment. On the other hand, overconsumption also implies unnecessary use of production capacities and resources, which also has a negative impact on the environment by greenhouse effects or water waste [2,5,7]. Besides, food waste produces big losses for different companies in the supply chain [8] and for the economy in general [9].

Several studies have shown that the final consumers play the most important role in reducing food waste $[4,10]$. The modernization and development of our society has created a fussy consumer, who produces a great amount of food leftovers every year [11]. Overcrowded schedules and an emancipation and convenience orientation cause consumers not to care anymore for the efficiency of 
bought and prepared food. Moreover, some consumers, in order to indulge themselves, have different pretentions regarding the products they eat. Besides, the relative cost of food related to the total income of the consumer decreases with the development of an economy [10,12], so that the waste of food does not produce big financial losses for the individuals, reducing their motivation to use food in an efficient manner.

Most of the studies related to food waste focus mainly on the assessment and characterization of food waste as well as on the factors that determine and favor this process. Studies investigating the influence of the cultural background on the phenomenon of food waste have hardly been found. Each culture has its own values, beliefs and habits related to food and therefore it is interesting to research whether this differentiation leads to different quantities of wasted food based on cultural characteristics. In this article, we focus on the influence of cultural values as described by Hofstede on the quantities of wasted food.

\section{Literature Review}

\subsection{Definition of Food Waste}

In spite of its importance, over time, there was no consensus for the term of "food waste", as it is defined in several ways depending on the place of occurrence, content or the nature of waste [1]. Besides, there are several terms with similar definitions that define the same fact, such as "food losses" or "food spoilage" [13]. The Food and Agriculture Organization of the United Nations (FAO) initially defined "food waste" as the entire edible material intended for human consumption that is discarded, lost, degraded or consumed by pests, which arises at any point in the food supply chain $[3,14,15]$. Several authors agree to this wide-sense definition expressing the main idea of food waste, which includes all food materials that are discarded, lost or uneaten [16-18].

A later definition of the Food and Agriculture Organization of the United Nations (FAO) makes the delimitation between food waste, food loss and food wastage [2]. According to this new definition, "food losses" refers to the decrease of quality of food that makes it unfit for human consumption because of several reasons, such as inefficiencies in the infrastructure or logistics of the supply chain, lack of technology, insufficient management skills and knowledge of supply chain actors as well as lack of access to markets [2,19-21]. According to this new definition, "food waste" refers to the food discarded because it has been spoiled or it has been kept beyond the expiry date for reasons such as oversupply or inefficient consumer' shopping and eating habits $[2,20,22,23]$. Besides the definition which includes all types of discarded food into the concept of food waste [16-18], the difference between food losses and food waste refers to the different phases during which the food material is discarded from consumption for several reasons. So, "food losses" refers to the phases in the supply chain, before reaching the final consumers $[2,19,20]$, while "food waste" refers to the discarded food by the final consumer $[2,20,22,23]$. "Food wastage" refers to spoiled food, including both food waste and food losses [2]. Meanwhile, the European Union has elaborated on the Commission Delegated Decision (EU) 2019/1597 of 3 May 2019 supplementing the Directive 2008/98/EC of the European Parliament and of the Council, by which food waste measurement is regulated for the member states. According to this directive, there are established the food types that are considered waste at all levels of the supply chain. Moreover, there are provided several methods and instruments for the measurement of food waste at each level of the supply chain, including primary production, processing and manufacturing; retail and other distributors of food; restaurants and food services as well as households [24].

Besides the wide range of definitions given to food waste and food losses, there are several classifications and characterizations of these concepts [1]. A first classification refers to the stage of the supply chain in which food losses can occur. Food losses in the supply chain can occur in the production, post-harvesting and processing stages $[13,15]$. Food waste can occur both at the consumer level and in the retail phase $[13,15]$. In order to reduce the quantity of wasted food in the retail phase, different methods [25] have been initiated, such as increasing of shelf life of food products [26] or using 
better packages that increase the length of freshness of food products $[27,28]$. At the consumer level, there are also several habits, such as buying more food than needed, cooking more food than needed or not eating food after it has been cooked [7,29]. Food waste can be categorized as kitchen waste (generated during cooking), service waste (generated because of overproduction) and leftovers [30]. Another classification refers to voluntary or involuntary food waste depending on the cause that has led to the discarded food. Another categorization refers to avoidable, possibly avoidable and unavoidable food waste depending on the possibility of reusing the food material [31,32]. Besides the different types of food waste, it is also important to analyze the factors that favor or inhibit this phenomenon.

\subsection{Factors Affecting the Waste of Food}

In an era when discussions about the food security of the population happen frequently, it is important to analyze the factors that influence the quantity of wasted food. Food waste occurs in the entire supply chain from agricultural production, in the post-harvest handling and storage and in the distribution and the final consumption. It is estimated that the biggest quantity of wasted food is produced by the final consumer [33]. In a research about the consumers in The European Union, Stenmarck et al. (2016) estimated that $53 \%$ of the avoidable wasted food is produced by the final consumers. This result is confirmed by the Food and Agricultural Organization, according to which one-third of the food produced for human consumption is lost or wasted every year [1,19].

There are several factors affecting food waste. Studies show that more food waste occurs in developed countries, compared to developing countries [12]. According to a study conducted by Gustavsson et al. (2011), the amount of wasted food is 12 times higher in industrialized countries compared to developing countries [19,33]. The climate and the availability of agricultural production [32] are also factors affecting food waste. For instance, more food is wasted in the summer [1], probably because of the fact that food is quicker to perish in warm temperatures. In spite of the fact that regional and national surveys on food waste have gained importance in the scientific literature, there are few comparative studies on food waste and the factors affecting it. This is because of the wide range of definitions attributed to the terms "food waste" and "food losses" [4,33]. However, most of the studies focus on researching the behavior of the stakeholders in the entire supply chain [1,34].

The quantity of wasted food is determined by a wide range of socio-demographic factors. Studies have shown that households with a higher number of people waste more food in comparison to small ones [12,35,36]. Older people [36] and price-oriented consumers [37] waste less food, while households with young children and higher incomes have the tendency to waste more food $[12,29,36,38]$. Apparently, the relation between income and food waste is a complicated one. There are groups of consumers with under-average income that have the tendency to buy higher amounts of lower quality food and afterwards not consume it $[29,39]$. On the other hand, there are consumers who are more concerned about healthy and safe foods, but still have the tendency to produce more food waste [40]. Gender also plays an important role [41] in the sense that women waste less food. Young adults have the tendency to waste more food [10]. Another issue is the food waste in schools and canteens, where young consumers play an important role [42].

At a consumer level, several authors state that food waste is determined by inefficient consumption patterns, by buying more products than needed. Especially in developed countries, the highest percentage of food waste happens at the consumer level [43], because food waste does not cost much [10] and therefore there is no financial incentive to reduce this phenomenon. Regarding consumption patterns, three periods for possible food waste have been determined: the time from buying to preparation, the time from preparation to serving and the time after serving. In all these phases of planning, storing and consuming the food, the consumer has a behavior that favors food waste [7]. According to McCarthy and Liu (2017), the main reason for food waste is the fact that the food has not been eaten before it spoils or that it has been forgotten in the fridge. A third reason is the fact that the consumers have the tendency to buy products with a short shelf life [29]. 
In their research, Gaiani et al. (2018) identify seven typologies of food wasters, based on a survey carried out in Italy. The first typology is the conscious-fussy consumer, who wastes food because he/she does not like how it looks. The second category refers to the exaggerating cook, who wastes food because he/she buys and cooks too much. The third category is the conscious-forgetful consumer, who forgets what he/she has in the fridge and therefore forgets to eat it. The unskilled-cook creates food-waste because they are unable to cook it properly and they are also not able to evaluate the quantities. The confused consumer refers to a group of buyers who do not understand the labelling of the products. The exaggerated shopper has the tendency to buy too much, because he/she is afraid of not having enough food. The seventh category includes the frugal consumer, who has the fewest quantity of wasted food [43].

Psychological factors like emotion, consciousness and guilt play an important role in changing the behavior of consumers towards food waste. According to a research conducted by Richter and Bokelmann (2018), the consumer feels guilty and has a bad conscience when wasting food because of the poverty and hunger in the world and less because of environmental reasons. Moreover, reduced cost of food is one of the main motivators for reducing food waste [36,37].

Zhang et al. (2018) point out the importance of cultural influences on the quantity of wasted food. On one hand, they state that in developing countries the quantity of wasted food is smaller. On the other hand, there are certain cultural values such as hospitality, which play an important role in food wasting. In some countries there is a social pressure to cook more food when guests are invited, in order not to "lose face" [12]. Food waste also depends on the category of the product. According to Gaiani et al. (2018), vegetables are the product group with the highest percentage of food waste. According to Florkowski et al. (2018), consumers with high incomes waste lower amounts of fruit and vegetables in comparison to other consumer categories. Several authors believe that food waste differs depending on region $[12,44,45]$ and therefore also depending on the national culture. In spite of these results, the influence of cultural values on quantities of wasted food is still a less debated topic. Several studies point out the fact that cultural values affect the behavior and attitudes of consumers for different product groups, therefore it should also influence the quantities of wasted food.

\subsection{Cultural Determinants of Consumer Typologies and Behavior}

Hofstede's cultural dimensions is one of the most comprehensive models describing the differences between the characteristics of individuals in different countries [46]. This model defines six characteristics which differentiate national cultures and the behavior, values, beliefs and life approaches of their individuals [47].

The power distance index describes the attitude of individuals towards the distribution of power within the society. In countries with a high power distance, less powerful members of the society accept more easily the inequalities in the society and they accept the hierarchical order. In opposition to this, in countries with a low power distance index, the members of the society strive to have an equal distribution of power within the society and decisions are taken in a more democratic way [46].

The individualism-collectivism dichotomy characterizes the relation between the individual and the collectivity to which he belongs. In countries with a high individualism index, the emphasis is put on the importance of the individual and its immediate family and their rights. In opposition to this, in countries with a low individualism index (collectivism societies), the interest of the group is more important in comparison to the rights of the individual. In collectivistic nations there is an extended view of the concept of family [46].

The masculinity dimension refers to the preference and motivation of a nation towards achievements or quality of life. Masculine countries (also called tough countries) are more oriented to success in the society by focusing on achievements, heroism and material reward. In opposition to this, feminine countries put the emphasis on quality of life, cooperation, modesty and caring for the weak [46]. 
The uncertainty index describes the way in which the individuals of a nation deal with ambiguity and the unpredictability of the future. Countries with a high uncertainty index are oriented towards the reduction of unpredictability of the future by introducing rigid codes for beliefs and behavior. On the other hand, countries with a low uncertainty avoidance index feel comfortable with and accept changes more easily. They usually let the future happen without planning it in advance [46].

The long term orientation describes the relation of nations to time. Countries with a high long term orientation index are more pragmatic and focus on the future. Countries with low values for this cultural dimension are more anchored in the past by honoring traditions, by being reluctant to change and by preserving and fulfilling social obligations [46].

The indulgence index refers to the way in which human drives are accepted. Societies with a high indulgence index enjoy life and having fun. In opposition to this, countries with a low indulgence index have restraints and control their impulses by having strict social norms [46].

One of the biggest critiques of Hofstede's cultural dimensions refers to the fact that they define only an average value of a nations' dimensions, without showing particular characteristics of its individuals [47]. In spite of this fact, the cultural dimensions still show a certain tendency to adopt a certain behavior or attitude, which can be more frequent in some countries in comparison to others [48]. DeMooij (2013) points out that intercultural research should not be compared to national research, where the characteristics of the individuals can be determined. Even though individuals within a culture are different, they are still guided by cultural priorities and values [48].

\section{Methodology}

\subsection{Hypotheses}

The objective of this paper is to determine the impact of the national culture on the food-wasting patterns of consumers concerning fruit and vegetables. The aim of this research is to determine the characteristics of a society that affect the food waste produced by consumers. In order to test if the national culture has an impact on the waste of food, whether any of the cultural characteristics of a society according to Hofstede's cultural dimensions model $[49,50]$ has an impact on the waste of fruit and vegetables was analyzed. Based on this assumption, the following hypotheses were developed:

Hypotheses 1 (H1). The quantity of food waste of fruit (except wine products) is influenced by the characteristics of the national culture according to Hofstede's model.

Hypotheses 2 (H2). The quantity of food waste of vegetables is influenced by the characteristics of the national culture according to Hofstede's model.

In order to test these hypotheses, whether any of the six cultural dimensions of Hofstede's model has a significant impact on the quantity of food waste for the tested product groups was analyzed. If at least one of the cultural dimensions had a significant impact on the quantity of wasted food for any of the four product groups, the hypothesis regarding this food type was confirmed.

\subsection{Panel Regression Models}

In order to test Hypotheses $\mathrm{H} 1$ and $\mathrm{H} 2$, two panel regression models were developed, with the quantity of food waste for the analyzed product group as a dependent variable and Hofstede's cultural dimensions as independent variables. Taking into consideration the variety of definitions on food waste, the data in this paper rely on the initial definition by the FAO, referring to a wider understanding of the concept of food waste [14]. In each of the models, there were included the following control variables: gross domestic product per capita, the quantity of consumed food from that category and the quantity of imported goods for that product category. The quantity of wasted food should depend on the consumed quantity. The imports were included in the model in order to analyze the availability and difficulty of procuring a certain food type and its influence on the wasted quantity. The gross 
domestic product per capita was included as a control variable as an indicator for the well-being and economic power of each analyzed country. For each of the two models, a linear relation was assumed.

For Hypothesis H1, regarding the influence of Hofstede's cultural dimensions on the quantity of wasted fruit, the following panel regression (Equation (1)) was developed:

$$
\begin{aligned}
& \mathrm{W}_{\mathrm{FRUITS}, \mathrm{it}}=\beta_{1 \mathrm{f}} \mathrm{X}_{\mathrm{POWD}, \mathrm{it}}+\beta_{2 \mathrm{f}} \mathrm{X}_{\mathrm{IND}, \mathrm{it}}+\beta_{3 \mathrm{f}} \mathrm{X}_{\mathrm{MASC}, \mathrm{it}}+\beta_{4 \mathrm{f}} \mathrm{X}_{\mathrm{LTO}, \mathrm{it}}+\beta_{5 \mathrm{f}} \mathrm{X}_{\mathrm{UAV}, \mathrm{it}} \\
& +\beta_{6 \mathrm{f}} \mathrm{X}_{\mathrm{INDULG}, \mathrm{it}}+\beta_{7 \mathrm{fc}} \mathrm{X}_{\mathrm{GDPPC}, \mathrm{it}}+\beta_{8 \mathrm{fc}} \mathrm{C}_{\mathrm{FRUITS}, \mathrm{it}}+\beta_{9 \mathrm{fc}} \mathrm{I}_{\mathrm{FRUITS}, \mathrm{it}}+\mathrm{c}_{1 \mathrm{f}}
\end{aligned}
$$

where $\mathrm{i}=$ entity and $\mathrm{t}=$ time.

The panel regression model Equation (1) has the dependent variable quantity of food waste of fruit $\left(\mathrm{W}_{\mathrm{FRUITS}, \mathrm{it}}\right)$ and the cultural dimensions as independent variables $(\mathrm{X} \alpha$, it). For each of the independent variables, the $\beta$-coefficients $\beta_{\mathrm{jf}}$ and $\mathrm{j}=1, \ldots, 6$ were defined. In order to increase the validity of the model, the following control variables were included: gross domestic product per capita $\left(\mathrm{X}_{\mathrm{GDPPC}, \mathrm{it}}\right)$, the consumption of fruit $\left(\mathrm{C}_{\mathrm{FRUITS}, \mathrm{it}}\right)$ and the quantity of imported fruit ( $\left.\mathrm{I}_{\mathrm{FRUITS}, \mathrm{it}}\right)$, as well as the constant $c_{1 f}$. For each of the control variables, the $\beta$-coefficients $\beta_{j f}$ and $j=7, \ldots, 9$ were defined.

For Hypothesis H2, regarding the influence of the cultural dimensions on the quantity of wasted vegetables, the panel regression model presented in Equation (2) was developed:

$$
\begin{aligned}
& W_{V E G E T A B L E S, i t}=\beta_{1 \mathrm{v}} X_{\text {POWD,it }}+\beta_{2 v} X_{I N D, i t}+\beta_{3 v} X_{M A S C, i t}+\beta_{4 v} X_{L T O, i t}+\beta_{5 v} X_{U A V, i t} \\
& +\beta_{6 v} X_{I N D U L G, i t}+\beta_{7 v c} X_{G D P P C, i t}+\beta_{8 v c} C_{V E G E T A B L E S, i t}+\beta_{9 v} I_{V E G E T A B L E S, i t}+c_{1 v}
\end{aligned}
$$

where $\mathrm{i}=$ entity and $\mathrm{t}=$ time.

For this panel regression model, the dependent variable is the quantity of vegetable food waste $\left(\mathrm{W}_{\text {VEGETABLES,it }}\right)$ and Hofstede's cultural dimensions are the independent variables $(\mathrm{X} \alpha$, it). Each of the independent variables has $\beta$-coefficients $\beta_{j v}$ and $j=1, \ldots, 6$. In this regression model, the following control variables were included: gross domestic product per capita $\left(\mathrm{X}_{\mathrm{GDPPC}, \mathrm{it}}\right)$, the consumption of vegetables $\left(C_{\text {VEGETABLES }, i t}\right)$, the quantity of imported vegetables $\left(I_{V E G E T A B L E S, i t}\right)$ and their $\beta$-coefficients $\beta_{\mathrm{jv}}$ and $\mathrm{j}=7, \ldots, 9$. For this model, the constant $\mathrm{c}_{1 \mathrm{v}}$ was defined.

\subsection{Data Collection}

The data included in the testing of the two panel regression models was collected for the period 2008-2013, for the following 28 European countries: Austria, Belgium, Bulgaria, Croatia, Czech Republic, Denmark, Estonia, Finland, France, Germany, Greece, Hungary, Ireland, Italy, Latvia, Lithuania, Luxembourg, Malta, Netherlands, Norway, Poland, Portugal, Romania, Slovakia, Slovenia, Spain, Sweden and the United Kingdom.

For the dependent variable quantities regarding the food waste of fruit and vegetables, as well as for the control variables related to the quantity of consumed products and the imported quantity of products from the two categories, data provided by the Food and Agriculture Organization of the United Nations (2018) [51] were used. The data for the cultural dimensions were collected from the homepage of Gert-Hofstede.com (2016) [52,53]. The data used in this analysis were used as were presented in 2016, by having a scale of 1-100 for each cultural dimension. The data for the control variable gross domestic product per capita were provided by Eurostat (2018) [54]. The descriptions of all variables used in the four panel regression models can be observed in Table 1. 
Table 1. Definition of variables.

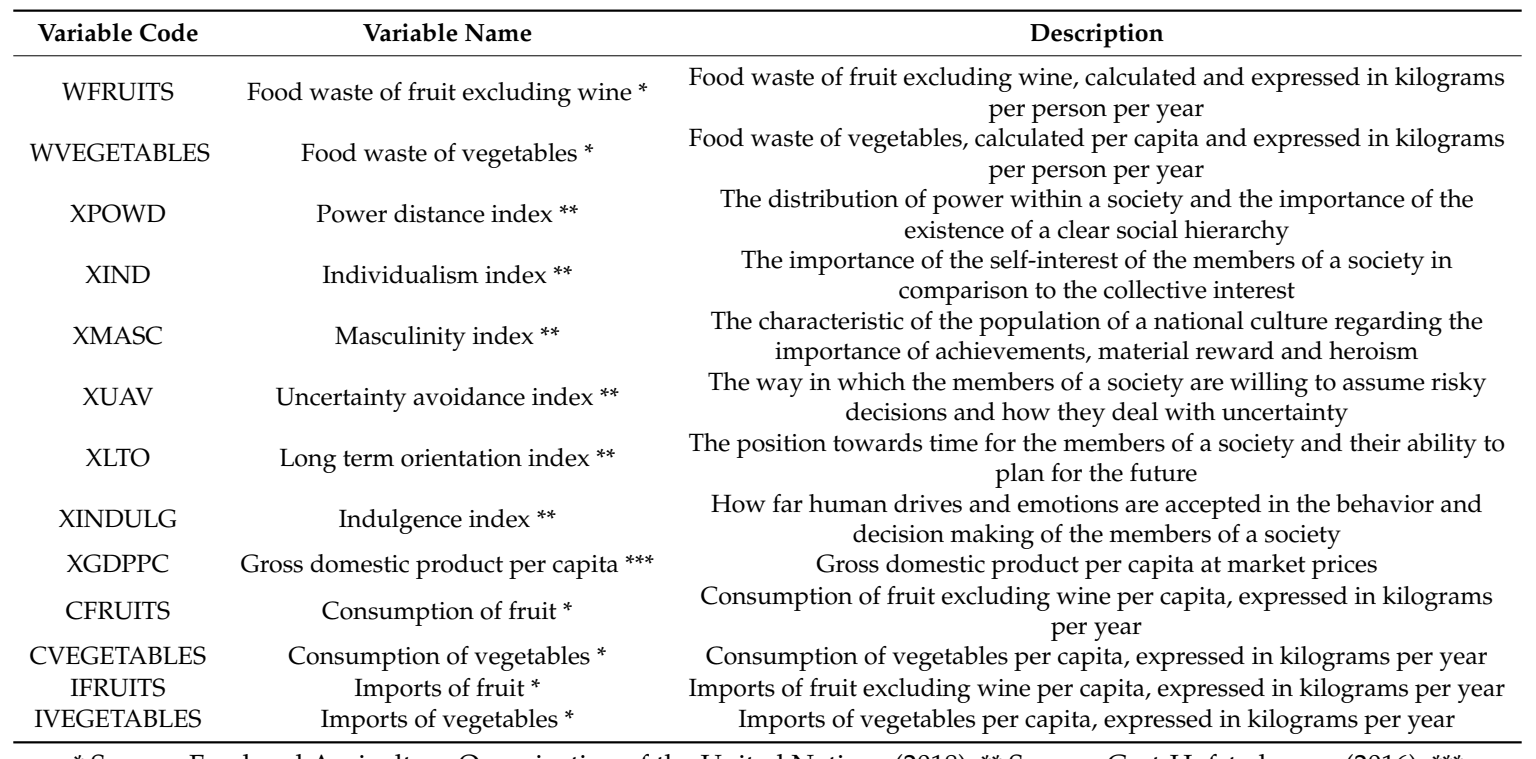

* Source: Food and Agriculture Organization of the United Nations (2018); ${ }^{* *}$ Source: Gert-Hofstede.com (2016); ***

Source: Eurostat Database (2018).

\section{Results}

\subsection{Descriptive Statistics}

The descriptive statistics for the variables included in the two panel regression models can be observed in Table 2. The data for the quantity of wasted food, the quantity of consumed food and imported quantities are based on data from the Food and Agriculture Organization of the United Nations [51]. According to the FAO, vegetables (11.03 kg/capita/year) have a higher waste volume compared to fruit $(6.37 \mathrm{~kg} / \mathrm{capita} /$ year). Vegetables $(112.72 \mathrm{~kg} / \mathrm{capita} /$ year) have a higher consumed volume compared to fruit (100.53 kg/capita/year), but fruit (126.88 kg/capita/year) are more frequently imported in comparison to vegetables $(63.47 \mathrm{~kg} / \mathrm{capita} /$ year).

Table 2. Statistical variation of variables.

\begin{tabular}{ccccc}
\hline Variable & Mean & Minimum & Maximum & Standard Deviation \\
\hline Food waste of fruit * & 6.37 & 0.32 & 27.21 & 6.03 \\
Food waste of vegetables * & 11.03 & 1.53 & 39.46 & 8.28 \\
Power distance index ** & 50.71 & 11 & 100 & 20.48 \\
Individualism index ** & 59.00 & 27 & 89 & 17.34 \\
Masculinity index ** & 44.64 & 5 & 100 & 24.78 \\
Uncertainty avoidance index ** & 69.85 & 23 & 100 & 21.59 \\
Long term orientation index ** & 56.71 & 24 & 83 & 16.63 \\
Indulgence index ** & 43.85 & 13 & 78 & 19.15 \\
GDPPC (control)** & 16.95 & 7.5 & 29.5 & 5.31 \\
Fruit consumption (control)* & 100.53 & 34.31 & 206.23 & 38.13 \\
Vegetable consumption (control)* & 112.72 & 60.46 & 246.32 & 40.39 \\
Imports of fruit (control)* & 126.88 & 20.03 & 608.15 & 118.16 \\
Imports of vegetables (control) * & 63.47 & 14.28 & 192.18 & 39.13 \\
\hline
\end{tabular}

* Source: Food and Agriculture Organization of the United Nations (2018); ** Source: Gert-Hofstede.com (2016);

*** Source: Eurostat Database (2018).

For Hofstede's cultural dimension the following values were calculated, based on data from Gert-Hofstede.com (2016) [52] and presenting the cultural variety of the analyzed countries. The maximum value for the power distance index was registered for Slovakia, while the minimum value of 11 was registered in Austria. United Kingdom had the highest value (89) for the individualism index, 
while Portugal and Slovenia had the lowest value (27) for this cultural dimension. The maximum value of 100 for the masculinity index was reached in Slovakia, while the minimum value of 5 was reached in Sweden. Denmark had the minimum value of 23 for the uncertainty avoidance index, while Greece achieved the maximum value of 100 . The country with the highest long term orientation was Germany (83), while Ireland was the country with a small value for this indicator (24). The maximum value for the indulgence index was reached in Sweden (78), while the country with the smallest indulgence index was Latvia (13).

\subsection{Results of the Panel Regression Model for the Dependent Variable Food Waste of Fruit}

The results of the panel regression model, having the waste of fruit as a dependent variable and the cultural dimensions as independent variables, are presented below. Taking into consideration the fact that the cultural dimensions are constant over time, a panel analysis with random effect was applied. Both relations were tested with a single independent variable, as well as combined models. The control variables included in the model were the gross domestic product per capita, the consumption of fruit and the imported quantity of fruit. The results are illustrated in Table 3.

Table 3. Panel regression model for the dependent variable food waste of fruit.

\begin{tabular}{|c|c|c|c|c|c|c|}
\hline \multicolumn{7}{|c|}{ Dependent Variable: Food Waste of Fruit } \\
\hline & Model 1 & Model 2 & Model 3 & Model 4 & Model 5 & Model 6 \\
\hline Power distance & $\begin{array}{l}-0.034 \\
(-0.49)\end{array}$ & & & & & \\
\hline Individualism & $\begin{array}{l}-0.120 \\
(-1.47)\end{array}$ & $\begin{array}{l}-0.094 \\
(-1.45)\end{array}$ & $\begin{array}{c}-0.135 * * \\
(-2.29)\end{array}$ & & & \\
\hline Masculinity & $\begin{array}{l}0.005 \\
(0.13) \\
\end{array}$ & & & & & \\
\hline $\begin{array}{l}\text { Uncertainty } \\
\text { avoidance }\end{array}$ & $\begin{array}{c}0.130 * * \\
(2.15)\end{array}$ & $\begin{array}{c}0.125 * * \\
(2.37)\end{array}$ & & $\begin{array}{l}0.123^{* * * *} \\
(2.74)\end{array}$ & & $\begin{array}{c}0.161^{* * *} \\
(3.37)\end{array}$ \\
\hline Long-term orientation & $\begin{array}{l}0.040 \\
(0.56)\end{array}$ & & & & & \\
\hline Indulgence & $\begin{array}{c}0.147^{* *} \\
(1.98)\end{array}$ & $\begin{array}{c}0.138 * * \\
(2.27)\end{array}$ & & & $\begin{array}{l}0.044 \\
(0.68)\end{array}$ & $\begin{array}{l}0.126 \text { ** } \\
(2.04)\end{array}$ \\
\hline GDPPC & $\begin{array}{l}-0.139 \\
(-1.06)\end{array}$ & $\begin{array}{l}-0.126 \\
(-0.97)\end{array}$ & $\begin{array}{l}-0.075 \\
(-0.61)\end{array}$ & $\begin{array}{l}-0.060 \\
(-0.48)\end{array}$ & $\begin{array}{l}-0.178 \\
(-1.34)\end{array}$ & $\begin{array}{l}-0.143 \\
(-1.11)\end{array}$ \\
\hline Fruit consumption & $\begin{array}{c}0.052^{* * *} \\
(4.53)\end{array}$ & $\begin{array}{c}0.052 * * * \\
(4.66)\end{array}$ & $\begin{array}{c}0.052 * * * \\
(4.62)\end{array}$ & $\begin{array}{c}0.055^{* * *} \\
(5.00)\end{array}$ & $\begin{array}{c}0.054^{* * *} \\
(4.76)\end{array}$ & $\begin{array}{c}0.054^{* * *} \\
(4.92)\end{array}$ \\
\hline Import of fruit & $\begin{array}{l}-0.012 \text { * } \\
(-1.92)\end{array}$ & $\begin{array}{c}-0.011 \text { ** } \\
(-2.00)\end{array}$ & $\begin{array}{l}-0.009 \\
(-1.62)\end{array}$ & $\begin{array}{c}-0.011 * * \\
(-2.10)\end{array}$ & $\begin{array}{l}-0.012 \text { ** } \\
(-2.08)\end{array}$ & $\begin{array}{c}-0.013^{* *} \\
(-2.33)\end{array}$ \\
\hline Constant & $\begin{array}{l}-4.423 \\
(-0.45)\end{array}$ & $\begin{array}{l}-4.699 \\
(-0.65)\end{array}$ & $\begin{array}{c}11.55^{* * *} \\
(3.14)\end{array}$ & $\begin{array}{c}-5.39 \\
(-1.26)\end{array}$ & $\begin{array}{c}3.52 \\
(-1.15)\end{array}$ & $\begin{array}{c}-12.04^{* *} \\
(-2.26)\end{array}$ \\
\hline Random effect & Yes & Yes & Yes & Yes & Yes & Yes \\
\hline Wald-chi2 & $38.10 * * *$ & $40.57^{* * *}$ & $29.59^{* * *}$ & $32.36^{* * *}$ & $23.74^{* * *}$ & $37.31^{* * *}$ \\
\hline R-sq & 0.507 & 0.496 & 0.326 & 0.374 & 0.182 & 0.448 \\
\hline rho & 0.941 & 0.932 & 0.941 & 0.937 & 0.954 & 0.936 \\
\hline Observations & 162 & 162 & 162 & 162 & 162 & 162 \\
\hline
\end{tabular}

Note: ${ }^{*}$ represents $p<0.1,{ }^{* *} p<0.05,{ }^{* * *} p<0.01$; values between parentheses represent $\mathrm{z}$-values.

For this analysis, a deductive method was applied by first testing the combined panel regression model. The first tested model had the waste of fruit as a dependent variable and all cultural dimensions as independent variables. The Wald-chi2 value showed a high significance ( $\mathrm{W}=38.1, p=0.000)$ for the entire relation, but not all the $\beta$-coefficients had a significant result (model 1 ). The uncertainty avoidance index $\left(\beta_{4 \mathrm{f}}=0.130, \mathrm{z}=2.15, p=0.032<0.05\right)$ and the indulgence index $\left(\beta_{6 \mathrm{f}}=0.147, \mathrm{z}=1.98\right.$, 
$p=0.048<0.05)$ were the cultural dimensions with significant $\beta$-coefficients in this panel regression. The individualism index also had an acceptable significance $\left(\beta_{2 \mathrm{f}}=-0.120, \mathrm{z}=-1.47, p=0.140<0.15\right)$; therefore, it was considered for the further analysis. The power distance index $\left(\beta_{1 \mathrm{f}}=-0.034, \mathrm{z}=-0.49\right.$, $p=0.626>0.1)$, the masculinity index $\left(\beta_{3 \mathrm{f}}=0.005, \mathrm{z}=0.13, p=0.898>0.1\right)$ and the long term orientation index $\left(\beta_{5 \mathrm{f}}=0.040, \mathrm{z}=0.56, p=0.579>0.1\right)$ did not have significant coefficients; consequently, they were not considered for the other analyses. The $R$-square value $\left(R^{2}=0.507\right)$ and the rho $=0.941$ confirm the fact that the cultural dimensions have an influence on the consumers' behavior regarding the waste of fruit.

The panel regression analysis with the uncertainty avoidance index, the indulgence index and the individualism index as independent variables (model 2) had a significant Wald-chi2 value ( $\mathrm{W}=40.57$, $p=0.000)$ and a high $R$-square value $\left(R^{2}=0.496\right)$. Taking into consideration the fact that the $R$-square for model 2 was almost as high as for model 1, it can be stated that these three cultural dimensions had a great influence on the quantity of wasted fruit. For this model, the uncertainty avoidance $\left(\beta_{4 \mathrm{f}}=0.125, \mathrm{z}=2.37, p=0.018<0.05\right)$ and indulgence $\left(\beta_{6 \mathrm{f}}=0.138, \mathrm{z}=2.27, p=0.023<0.05\right)$ indexes had a significant $\beta$-coefficient, while the individualism index $\left(\beta_{2 \mathrm{f}}=-0.094, \mathrm{z}=-1.45, p=0.148<0.15\right)$ had an acceptable significance for the $\beta$-coefficient.

Starting from this result, the single-variables relations were tested, having the waste of fruit as dependent variable and each of the influencing cultural dimensions as single independent variables (excluding the control variables). As was expected, the uncertainty avoidance index had a significant influence on the waste of fruit by having a Wald-chi2 $=32.36(p=0.000)$ and $\beta$-coefficient $\beta_{4 \mathrm{f}}=0.123$, $(z=2.74, p=0.006<0.01)$ in the relation in model 4 . The relation had strong values for the control variables of fruit consumption $\left(\beta_{8 \mathrm{fc}}=0.055, \mathrm{z}=5.00, p=0.000\right)$ and import of fruit $\left(\beta_{9 \mathrm{fc}}=-0.011\right.$, $\mathrm{z}=-2.10, p=0.036<0.05)$. The $\mathrm{R}$-square value $\left(\mathrm{R}^{2}=0.374\right)$ confirms the influence of the uncertainty avoidance index on the quantity of food waste of fruit. The fact that the value of $R^{2}=0.374$ in model 4 is lower than the one in model 2 shows that other cultural dimensions also have an influence on the dependent variable.

In model 3, the single-variable relation between the food waste of fruit as a dependent variable and the individualism index as an independent variable is presented. The Wald-chi2 value $(\mathrm{W}=29.59$, $p=0.000)$ and the $\beta$-coefficient for the individualism index $\left(\beta_{2 \mathrm{f}}=-0.135, \mathrm{z}=-2.29, p=0.022<0.05\right)$ confirm the significance of the panel regression. The $R$-square value $\left(R^{2}=0.326\right)$ also confirms the influence of this independent variable on the food waste of fruit.

The overall panel regression model with the indulgence index as a single independent variable has, on one hand, a significant value for the Wald-chi2 $(\mathrm{W}=23.74, p=0.001)$ and for $\mathrm{R}$-square value $\left(R^{2}=0.182\right)$. On the other hand, the $\beta$-coefficient $\left(\beta_{6 f}=0.044, z=0.68, p=0.497\right)$ for the variable indulgence index showed no significant influence on the dependent variable. In spite of this result, in the combined models presented in Table 3, having the indulgence index as one of the variables proved significant results. The indulgence index did not directly have an influence on the quantity of wasted fruit, but it can probably be a catalyzer in combination with other cultural dimensions.

Model 6 contains the uncertainty avoidance and indulgence indexes as independent variables. The Wald-chi2 value for this model $(\mathrm{W}=37.31, p=0.000)$ and the $\mathrm{R}$-square $\left(\mathrm{R}^{2}=0.448\right)$ show its high significance. The $\beta$-coefficients for the two independent variables had significant values $\left(\beta_{4 \mathrm{f}}=0.161\right.$, $\mathrm{z}=3.37$, and $p=0.001<0.1$ for uncertainty avoidance; and $\beta_{6 \mathrm{f}}=0.126, \mathrm{z}=2.04$, and $p=0.041<0.05$ for indulgence), showing their complementarity.

Taking into consideration all these, it can be considered that the uncertainty avoidance index has a significant influence on the quantity of wasted fruit. The indulgence index has a complementary influence on the dependent variable food waste of fruit, while the individualism index has a moderate influence. For the other cultural dimensions, no significant influence was determined. Starting from the logical assumption that if only one of the cultural dimensions influences the dependent variable, the national culture has a significant influence on the quantity of wasted fruit, Hypothesis $\mathrm{H} 1$ is confirmed. 


\subsection{Results of the Panel Regression Model for the Dependent Variable Food Waste of Vegetables}

In this section, the results of the panel regression models with the food waste of vegetables as dependent variable and Hofstede's cultural dimensions as independent variables (model 7) are presented. This model had a high significance $(W=68.44, p=0.000)$, but not all $\beta$-coefficients were significant. As can be observed in Table 4 , the uncertainty avoidance index $\left(\beta_{4 v}=0.218, z=3.12\right.$, $p=0.002)$ is the cultural dimension with the most significant influence on the quantity of wasted vegetables. The indulgence index is another variable with a significant $\beta$-coefficient $\left(\beta_{6 \mathrm{v}}=0.135, \mathrm{z}=1.71\right.$, $p=0.088<0.1)$. In opposition to this, all the other cultural dimensions did not have a significant $\beta$-coefficient. Therefore, the power distance $\left(\beta_{1 \mathrm{v}}=-0.024, \mathrm{z}=-0.31, p=0.754\right)$, individualism $\left(\beta_{2 \mathrm{v}}=0.006, \mathrm{z}=0.06, p=0.948\right)$, masculinity $\left(\beta_{3 \mathrm{v}}=0.021, \mathrm{z}=0.45, p=0.655\right)$ and long term orientation $\left(\beta_{4 \mathrm{v}}=-0.076, \mathrm{z}=-0.94, p=0.350\right)$ indexes did not influence the quantity of wasted vegetables. It is also interesting to observe that, in spite of the fact that there were less variables which significantly influence the food waste of vegetables, both the Wald-chi2 ( $\mathrm{W}=68.44, p=0.000)$ and the R-square $\left(R^{2}=0.592\right)$ had higher values in comparison to the models with the waste of fruit as independent variables $\left(\mathrm{W}=38.10, p=0.000\right.$ and $\left.\mathrm{R}^{2}=0.507\right)$. Therefore, the influence from the cultural dimension on the waste of vegetables is stronger compared to their influence on the waste of fruit.

Table 4. Panel regression model for the dependent variable food waste of vegetables.

\begin{tabular}{|c|c|c|c|c|c|c|}
\hline \multicolumn{7}{|c|}{ Dependent Variable: Food Waste of Vegetables } \\
\hline & Model 7 & Model 8 & Model 9 & Model 10 & Model 11 & Model 12 \\
\hline Power distance & $\begin{array}{l}-0.024 \\
(-0.31)\end{array}$ & & & & & \\
\hline Individualism & $\begin{array}{l}0.006 \\
(0.06)\end{array}$ & & & & & \\
\hline Masculinity & $\begin{array}{l}0.021 \\
(0.45)\end{array}$ & & & & & \\
\hline $\begin{array}{l}\text { Uncertainty } \\
\text { avoidance }\end{array}$ & $\begin{array}{c}0.218^{* * *} \\
(3.12)\end{array}$ & $\begin{array}{l}0.210 * * * \\
(3.93)\end{array}$ & $\begin{array}{c}0.157 \text { *** } \\
(3.21)\end{array}$ & & & $\begin{array}{c}0.214^{* * *} \\
(4.11)\end{array}$ \\
\hline Long-term orientation & $\begin{array}{l}-0.076 \\
(-0.94)\end{array}$ & $\begin{array}{l}-0.067 \\
(-0.95)\end{array}$ & & $\begin{array}{l}-0.115 * \\
(-1.65)\end{array}$ & & \\
\hline Indulgence & $\begin{array}{l}0.135 * \\
(1.71)\end{array}$ & $\begin{array}{c}0.146^{* *} \\
(2.12)\end{array}$ & & & $\begin{array}{l}0.077 \\
(1.24)\end{array}$ & $\begin{array}{c}0.173 * * * \\
(2.85)\end{array}$ \\
\hline GDPPC & $\begin{array}{l}-0.096 \\
(-0.96) \\
\end{array}$ & $\begin{array}{l}-0.085 \\
(-0.85) \\
\end{array}$ & $\begin{array}{l}0.004 \text { * } \\
(0.04)\end{array}$ & $\begin{array}{l}-0.088 \\
(-0.88)\end{array}$ & $\begin{array}{c}-0.098 \text { ** } \\
(-0.95)\end{array}$ & $\begin{array}{l}-0.078 \\
(-0.79) \\
\end{array}$ \\
\hline $\begin{array}{c}\text { Vegetables } \\
\text { consumption }\end{array}$ & $\begin{array}{c}0.049^{* * *} \\
(6.07)\end{array}$ & $\begin{array}{c}0.050 * * * \\
(6.18)\end{array}$ & $\begin{array}{c}0.053^{* * *} \\
(6.42)\end{array}$ & $\begin{array}{c}0.054^{* * *} \\
(6.54)\end{array}$ & $\begin{array}{c}0.055^{* * *} \\
(6.74)\end{array}$ & $\begin{array}{c}0.051 * * * \\
(6.34)\end{array}$ \\
\hline Import of vegetables & $\begin{array}{l}0.011 \\
(0.97)\end{array}$ & $\begin{array}{l}0.010 \\
(0.86)\end{array}$ & $\begin{array}{l}0.006 \\
(0.55)\end{array}$ & $\begin{array}{l}0.010 \\
(0.88)\end{array}$ & $\begin{array}{l}0.006 \\
(0.52)\end{array}$ & $\begin{array}{l}0.007 \\
(0.61)\end{array}$ \\
\hline Constant & $\begin{array}{l}-10.60 \\
(-1.01)\end{array}$ & $\begin{array}{l}-11.12 \\
(-1.41)\end{array}$ & $\begin{array}{c}-6.44 \\
(-1.57)\end{array}$ & $\begin{array}{c}12.29 * * * \\
(2.62)\end{array}$ & $\begin{array}{c}2.62 \\
(0.86)\end{array}$ & $\begin{array}{c}-16.5^{* * *} \\
(-3.07)\end{array}$ \\
\hline Random effect & Yes & Yes & Yes & Yes & Yes & Yes \\
\hline Wald-chi2 & $68.44^{* * *}$ & $72.94^{* * *}$ & $62.64^{* * *}$ & $51.42^{* * *}$ & $49.86^{* * *}$ & $73.23^{* * *}$ \\
\hline R-sq & 0.592 & 0.590 & 0.496 & 0.435 & 0.499 & 0.583 \\
\hline rho & 0.976 & 0.972 & 0.970 & 0.976 & 0.976 & 0.971 \\
\hline Observations & 168 & 168 & 168 & 168 & 168 & 168 \\
\hline
\end{tabular}

Note: * represents $p<0.1,^{* *} p<0.05,{ }^{* * *} p<0.01$; values between parentheses represent $\mathrm{z}$-values.

In order to describe the influence of each of the cultural dimensions on the waste of vegetables, we analyzed the single-variable regressions. As can be observed in Table 4, the panel regression with the uncertainty avoidance index as an independent variable had a high significance $(\mathrm{W}=62.64, p=0.000)$, 
and it had a great influence on the quantity of wasted food $\left(R^{2}=0.496\right)$. The $\beta$-coefficient for the uncertainty avoidance index $\left(\beta_{4 v}=0.157, z=3.21, p=0.001\right)$ also sustained the validity of the relation. Therefore, the uncertainty avoidance index was the cultural dimension that influenced the wasted quantity of vegetables most. In model 11, there can be observed the single-variable panel regression with the indulgence index as an independent variable. This relation also had a high significance by having a Wald-chi2 value of $49.86(p=0.000)$ and an R-square value of 0.499 . In opposition to the previous relation, the $\beta$-coefficient did not have a highly significant value $\left(\beta_{6 \mathrm{v}}=0.077, \mathrm{z}=1.24\right.$, $p=0.216)$.

In the model with both the uncertainty avoidance and the indulgence indexes as independent variables (model 12), both variables had significant $\beta$-coefficients. The uncertainty avoidance index had a $\beta_{4 v}=0.214(\mathrm{z}=4.11, p=0.000)$ and the indulgence index had a $\beta_{6 \mathrm{v}}=0.173(\mathrm{z}=2.85, p=0.004)$. Similar to the models with the quantity of wasted fruit as a dependent variable, the indulgence index had only a complementary influence. Therefore, it did not have a significant influence alone, but only in combination with the uncertainty avoidance index, by increasing its influence.

The other cultural dimensions did not have a significant influence on the food waste of vegetables. In spite of the fact that the general models were significant, for the single-variable models the $\beta$-coefficients did not have significant values for the power distance $\left(\beta_{1 \mathrm{v}}=-0.044, \mathrm{z}=0.78, p=0.435\right)$, individualism $\left(\beta_{2 \mathrm{v}}=-0.081, \mathrm{z}=-1.23, p=0.219\right)$ and masculinity $\left(\beta_{3 \mathrm{v}}=0.035, \mathrm{z}=0.77, p=0.443\right)$ indexes. The long term orientation $\left(\beta_{5 \mathrm{v}}=-0.115, \mathrm{z}=-1.65, p=0.099\right)$ index had significant values only in the single-variable model, but not in the combined models.

Taking all these into consideration, it can be stated that the uncertainty avoidance index had an influence on the food waste of vegetables. The indulgence index had a complementary influence to the uncertainty avoidance index. Based on the fact that two of the cultural dimensions influenced in a significant way the quantity of wasted vegetables, it can be considered that Hypothesis $\mathrm{H} 2$ is confirmed.

\section{Discussion}

The results of this research confirm the fact that national culture has an impact on the quantity of wasted fruit and vegetables. From a cultural perspective, the quantity of wasted fruit and vegetables is influenced by the uncertainty avoidance index, complemented by the indulgence index. Consumers with a higher uncertainty avoidance index and higher indulgence index have the tendency to waste more fruit and vegetables. Countries with a higher uncertainty avoidance index have the tendency to waste more food, both of the fruit and vegetable product categories. One possible explanation for this result is the fact that in countries with high uncertainty avoidance, individuals try to reduce ambiguity and unpredictable situations. Therefore, they buy more food than needed in order to have a certain reserve for unpredictable situations, but in most of the cases they do not use it and the food is wasted. Especially for fruit and vegetables, which are easily perishable, it is not possible to store them for a long period of time. This type of behavior is identified by Gaiani et al. (2018) and Schmidt and Matthies (2018), but not necessarily correlated with the national cultural values. Moreover, the complementary influence of the indulgence index determines that they buy products they like (in order to indulge themselves) without evaluating in a correct way the needed quantity. It must be mentioned that among the countries with a high uncertainty avoidance index are included the Mediterranean countries, which have a high production of fruit and vegetables. The high wasted quantities can be also explained by a bad management of the existing production. They waste fruit and vegetables because they have it and they do not store it in the appropriate conditions. The indulgence index has a catalyzing effect. They increase the effect of the uncertainty avoidance, but they do not have a significant influence of their own.

The limitations of the research include the fact that the data used in the panel regression refer to the entire society and are not analyzed for particular groups of consumers. In spite of this, the data on wasted food quantities can give valuable insights into the predisposing characteristics of nations and be a good starting point for further analysis regarding the influence of national cultural values 
on efficient food consumption patterns. Future research can focus on one hand on particular details of the behavior of different societies. On the other hand, it would be interesting to analyze whether food waste is a matter of a natural born characteristic or if it can be re-educated in order to reduce the quantities of wasted food.

\section{Conclusions}

This research confirms the fact that national culture, the values and the habits of different nations, impacts the quantities of wasted food. Similar to other fields, in order to reduce the quantities of wasted food, it is important to understand the cultural background and to educate the consumers according to their own cultural values [55] for having a pro-environmental behavior. For instance, in countries with a high uncertainty avoidance index and a high indulgence index, consumers should be trained to manage their resources in a better way. On the other hand, traditional countries should be trained to change their habits in order to buy products according to their needs. Several authors point out the fact that there is a "puzzle" of information regarding the behavioral and situational context in which food waste occurs [1]. In order to intervene and diminish food waste, policy makers should adopt several regulations regarding food safety and food loss prevention. The European Union has already set a series of sustainable goals, including a directive for the reduction of food waste [45]. Besides this, there are several non-profit organizations that implement strategies and programs in order to educate consumers for food waste prevention or to develop alternatives for the recycling and re-use of food waste [33]. Still, it will take some time until a unanimous definition of food waste is given, a clear classification of food waste types is made and adequate means for the collection of food leftovers are implemented.

In order to reduce the quantities of wasted food, it is important for both researchers and policy makers to match certain food-wasting patterns with consumers' or individuals' characteristics and profiles. Only in this way can certain measures be taken in order to avoid food waste. In this sense, this research offers a starting point for matching certain consumers' characteristics based on cultural values with certain wasting patterns.

Author Contributions: Conceptualization, C.P., R.S. and D.S.; methodology, C.P.; validation, C.P.; writing—original draft preparation, C.P., R.S. and D.S.; writing-review and editing, C.P. All authors have read and agreed to the published version of the manuscript.

Funding: This research received no external funding.

Conflicts of Interest: The authors declare no conflict of interest.

\section{References}

1. Roodhuyzen, D.M.A.; Luning, P.A.; Fogliano, V.; Steenbekkers, L.P.A. Putting together the puzzle of consumer food waste: Towards an integral perspective. Trends Food Sci. Technol. 2017, 68, 37-50. [CrossRef]

2. Food and Agriculture Organization of the United Nations (FAO). Food Wastage Footprint. Impacts on Natural Resources. 2013. Available online: http://www.fao.org/docrep/018/i3347e/i3347e.pdf (accessed on 21 December 2018).

3. Papargyropoulou, E.; Lozano, R.; Steinberger, J.K.; Wright, N.; Bin Ujang, Z. The food waste hierarchy as a framework for the management of food surplus and food waste. J. Clean. Prod. 2014, 76, 106-115. [CrossRef]

4. Stenmarck, A.; Jensen, C.; Quested, T.E.; Moates, G. Estimates of European Food Waste Levels. 2016. Available online: https://www.eu-fusions.org/phocadownload/Publications/Estimates\%20of\%20European\% 20food\%20waste\%20levels.pdf (accessed on 21 December 2018).

5. Chaboud, G.; Daviron, B. Food losses and waste: Navigating the inconsistencies. Glob. Food Secur. 2017, 12, 1-7. [CrossRef]

6. Heikkila, L.; Reinikainen, A.; Katajajuuri, J.M.; Silvennoinen, K.; Hartikainen, H. Elements affecting food waste in the food service sector. Waste Manag. 2016, 56, 446-453. [CrossRef] [PubMed] 
7. Schmidt, K.; Matthies, E. Where to start fighting the food waste problem? Identifying most promising entry points for intervention programs to reduce household food waste and overconsumption of food. Resour. Conserv. Recycl. 2018, 139, 1-14. [CrossRef]

8. Cicatiello, C.; Franco, S.; Pancino, B.; Blasi, E. The value of food waste: An exploratory study on retailing. J. Retail Consum. Serv. 2016, 30, 96-104. [CrossRef]

9. Trica, C.L.; Banacu, C.S.; Busu, M. Environmental factors and sustainability of the circular economy model at the European Union level. Sustainability 2019, 11, 1114. [CrossRef]

10. Nikolaus, C.J.; Nickols-Richardson, S.M.; Ellison, B. Wasted food: A qualitative study of U.S. young adults' perceptions, beliefs and behaviors. Appetite 2018, 130, 70-78. [CrossRef]

11. Thyberg, K.L.; Tonjes, D.J. Drivers of food waste and their implications for sustainable policy development, Resources. Conserv. Recycl. 2016, 106, 110-123. [CrossRef]

12. Zhang, H.; Duan, H.; Andric, J.M.; Song, M.; Yang, B. Characterization of household food waste and strategies for its reduction: A Shenzhen City case study. Waste Manag. 2018, 78, 426-433. [CrossRef]

13. Kummu, M.; De Moel, H.; Porkka, M.; Siebert, S.; Varis, O.; Ward, P.J. Lost food, wasted resources: Global food supply chain losses and their impacts on freshwater, cropland, and fertiliser use. Sci. Total Environ. 2012, 438, 477-489. [CrossRef]

14. Food and Agriculture Organization of the United Nations (FAO). Food Loss Prevention in Perishable Crops. FAO Agricultural Service Bulletin, no. 43. FAO Statistics Division. 1981. Available online: http://www.fao.org/3/s8620e/S8620E00.htm (accessed on 9 October 2019).

15. Parfitt, J.; Barthel, M.; MacNaughton, S. Food waste within food supply chains: Quantification and potential for change to 2050. Philos. Trans. R. Soc. B Biol. Sci. 2010, 365, 3065-3081. [CrossRef]

16. Gjerris, M.; Gaiani, S. Household food waste in Nordic countries: Estimations and ethical implications. Etikk i Praksis 2013, 7, 6-23. [CrossRef]

17. Monier, V.; Mudgal, S.; Escalon, V.; O'Connor, C.; Gibon, T.; Anderson, G.; Montoux, H. Preparatory Study on Food Waste across EU 27. European Commission. 2011. Available online: https://ec.europa.eu/environme nt/eussd/pdf/bio_foodwaste_report.pdf (accessed on 9 October 2019).

18. Nahman, A.; de Lange, W. Costs of food waste along the value chain: Evidence from South Africa. Waste Manag. 2013, 33, 2493-2500. [CrossRef]

19. Gustavsson, J.; Cederberg, C.; Sonesson, U.; Van Otterdijk, R.; Meybeck, A. Global Food Losses and Food Waste-extent, Causes and Prevention; Food and Agriculture Organization of the United Nations (FAO): Rome, Italy, 2011. Available online: http://www.fao.org/3/a-i2697e.pdf (accessed on 9 October 2019).

20. Lipinski, B.; Hanson, C.; Lomax, J.; Kitinoja, L.; Waite, R.; Searchinger, T. Reducing Food Loss and Waste. Working Paper, Installment 2 of Creating a Sustainable Food Future; World Resources Institute: Washington, DC, USA, 2013. Available online: https://pdf.wri.org/reducing_food_loss_and_waste.pdf (accessed on 9 October 2019).

21. Coca, V.; Dobrea, M.; Vasiliu, C. Towards a sustainable development of retailing in Romania. Amfiteatru Econ. 2013, 15, 583-602.

22. Grandhi, B.; Appaiah Singh, J. What a waste! A study of food wastage behavior in Singapore. J. Food Prod. Mark. 2015, 22, 471-485. [CrossRef]

23. Griffin, M.; Sobal, J.; Lyson, T.A. An analysis of a community food waste stream. Agric. Hum. Values 2009, 26, 67-81. [CrossRef]

24. Commission Delegated Decision (EU) 2019/1597 of 3 May 2019, Supplementing Directive 2008/98/EC of the European Parliament and of the Council as Regards a Common Methodology and Minimum Quality Requirements for the Uniform Measurement of Levels of Food Waste. Available online: https://eur-lex.euro pa.eu/legal-content/EN/TXT/PDF/?uri=CELEX:32019D1597\&from=EN (accessed on 17 November 2020).

25. Lagorio, A.; Pinto, R.; Golini, R. Food waste reduction in school canteens: Evidence from an Italian case. J. Clean. Prod. 2018, 199, 77-84. [CrossRef]

26. Eriksson, M.; Strid, I.; Hansson, P.A. Food waste reduction in supermarkets-Net costs and benefits of reduced storage temperature. Resour. Conserv. Recycl. 2016, 107, 73-81. [CrossRef]

27. Beitzen-Heineke, E.F.; Balta-Ozkan, N.; Reefke, H. The prospects of zero-packaging grocery stores to improve the social and environmental impacts of the food supply chain. J. Clean. Prod. 2017, 140, 1528-1541. [CrossRef]

28. Brancoli, P.; Rousta, K.; Bolton, K. Life cycle assessment of supermarket food waste. Resour. Conserv. Recycl. 2017, 118, 39-46. [CrossRef] 
29. McCarthy, B.; Liu, H.B. Food waste and the 'green' consumer. Aust. Mark. J. 2017, 25, 126-132. [CrossRef]

30. Katajajuuri, J.M.; Silvennoinen, K.; Hartikainen, H.; Heikkila, L.; Reinikainen, A. Food waste in the Finnish food chain. J. Clean. Prod. 2014, 73, 322-329. [CrossRef]

31. Quested, T.; Johnson, H. Household Food and Drink Waste in the UK: Final Report. Banbury: Wastes \& Resources Action Programme (WRAP). 2009. Available online: http://www.wrap.org.uk/sites/files/wrap/Ho usehold_food_and_drink_waste_in_the_UK_-_report.pdf (accessed on 9 October 2019).

32. Busu, M. Assessment of the impact of bioenergy on sustainable economic development. Energies 2019, $12,578$. [CrossRef]

33. Garcia-Herrero, I.; Hoehn, D.; Margallo, M.; Laso, J.; Bala, A.; Batlle-Bayer, L.; Fullana, P.; Vazquez-Rowe, I.; Gonzalez, M.J.; Durá, M.J.; et al. On the estimation of potential food waste reduction to support sustainable production and consumption policies. Food Policy 2018, 80, 24-38. [CrossRef]

34. Irani, Z.; Sharif, A.M.; Lee, H.; Aktas, E.; Topaloglu, Z.; Wout, T.; Huda, S. Managing food security through food waste and loss: Small data to big data. Comput. Oper. Res. 2018, 98, 367-383. [CrossRef]

35. Jörissen, J.; Priefer, C.; Bräutigam, K.-R. Food waste generation at household level: Results of a survey among employees of two European research centers in Italy and Germany. Sustainability 2015, 7, 2695-2715. [CrossRef]

36. Richter, B.; Bokelmann, W. The significance of avoiding household food waste-A means-end-chain approach. Waste Manag. 2018, 74, 34-42. [CrossRef]

37. Aschemann-Witzel, J.; Jensen, J.H.; Jensen, M.H.; Kulikovskaja, V. Consumer behaviour towards price-reduced suboptimal foods in the supermarket and the relation of food waste in households. Appetite 2017, 116, $246-258$. [CrossRef]

38. Dabija, D.C.; Bejan, B.M.; Dinu, V. How Sustainability Oriented is Generation Z in Retail? A Literature Review. Transform. Bus. Econ. 2019, 18, 150-155.

39. Setti, M.; Falasconi, L.; Segrè, A.; Cusano, I.; Vittuari, M. Italian consumers' income and food waste behavior. Br. Food J. 2016, 118, 1731-1746. [CrossRef]

40. Abdelradi, F. Food waste behaviour at the household level: A conceptual framework. Waste Manag. 2018, 71, 485-493. [CrossRef]

41. Principato, L.; Secondi, L.; Pratesi, C.A. Reducing food waste: An investigation on the behaviour of Italian youths. Br. Food J. 2015, 117, 731-748. [CrossRef]

42. Derqui, B.; Fernandez, V.; Fayos, T. Towards more sustainable food systems. Addressing food waste at school canteens. Appetite 2018, 129, 1-11. [CrossRef]

43. Gaiani, S.; Caldeira, S.; Adorno, V.; Segrè, A.; Vittuari, M. Food wasters: Profiling consumers' attitude to waste food in Italy. Waste Manag. 2018, 72, 17-24. [CrossRef]

44. Hanssen, O.J.; Syversen, F.; Sto, E. Edible food waste from Norwegian households-Detailed food waste composition analysis among households in two different regions in Norway. Resour. Conserv. Recycl. 2016, 109, 146-154. [CrossRef]

45. Florkowski, W.J.; Us, A.; Klepacka, A.M. Food waste in rural households support for local biogas production in Lubelskie Voivodship (Poland). Resour. Conserv. Recycl. 2018, 136, 46-52. [CrossRef]

46. Hofstede Insights. The 6 Dimensions of National Culture. 2018. Available online: https://www.hofstede-ins ights.com/models/national-culture/ (accessed on 12 December 2018).

47. Venaik, S.; Brewer, P. Critical issues in the Hofstede and GLOBE national culture models. Int. Mark. Rev. 2013, 30, 469-482. [CrossRef]

48. De Mooij, M. On the misuse and misinterpretation of dimensions of national culture. Int. Mark. Rev. 2013, 30, 253-261. [CrossRef]

49. Hofstede, G.; Hofstede, G.J.; Minkov, M. Cultures and Organizations: Software of the Mind; McGraw-Hill: New York, NY, USA, 2010.

50. Hofstede, G. Culture's Consequences: Comparing Values, Behaviors, Institutions, and Organizations Across Nations; Sage Publication: Thousand Oaks, CA, USA, 2001.

51. Food and Agriculture Organization of the United Nations. 2018. Food Balance Sheets (Europe). Available online: http://www.fao.org/faostat/en/\#data/FBS (accessed on 31 July 2018).

52. Gert-Hofstede.com. 2016. Cultural Dimension-National Culture. Available online: https://www.geert-hofste de.com/national-culture.html (accessed on 20 July 2016). 
53. Geerthofstede.com. 2018. Dimension Data Matrix. Available online: https://geerthofstede.com/research-and -vsm/dimension-data-matrix/ (accessed on 20 October 2018).

54. Eurostat. 2018. Main GDP Aggregates Per Capita (Code: Nama_10_pc). Available online: http://appsso.eur ostat.ec.europa.eu/nui/submitViewTableAction.do (accessed on 6 August 2018).

55. Pelau, C.; Pop, N.A. Implications for the energy policy derived from the relation between the cultural dimensions of Hofstede's model and the consumption of renewable energies. Energy Policy 2018, 118, 160-168. [CrossRef]

Publisher's Note: MDPI stays neutral with regard to jurisdictional claims in published maps and institutional affiliations.

(C) 2020 by the authors. Licensee MDPI, Basel, Switzerland. This article is an open access article distributed under the terms and conditions of the Creative Commons Attribution (CC BY) license (http://creativecommons.org/licenses/by/4.0/). 